\title{
correspondence
}

\section{Micromet programs in East Antarctica and Thailand}

Paul C. Dalrymple, U. S. Army Natick

Laboratories, Natick, Mass.

The Earth Sciences Laboratory of the U. S. Army Natick (Mass.) Laboratories has been conducting micrometeorological programs in two of the most severe climates that normal individuals would try to avoid, the extreme cold dry climate of interior East Antarctica and the hot humid climate of Southeast Asia. The program in East Antarctica, under the sponsorship of the National Science Foundation, has been conducted at Plateau, a station located at $3624 \mathrm{~m}\left(11,890^{\prime}\right)$ at $79^{\circ} 14^{\prime} \mathrm{S}, 40^{\circ} 30^{\prime} \mathrm{E}$. It is the United States counterpart to the extreme cold Russian station in Antarctica, Vostok. Although Plateau appears to have a colder mean annual temperature than Vostok, the absolute minimum record still belongs to the Soviet Union, $-88.4 \mathrm{C}(-127.1 \mathrm{~F})$, compared to Plateau's $-84.6 \mathrm{C}(-123.1 \mathrm{~F})$. The program in Southeast Asia is located on the so-called but misnamed Korat Plateau, $175 \mathrm{~km}$ northeast of Bangkok at an elevation of $530 \mathrm{~m}\left(14^{\circ} 30^{\prime} \mathrm{N}, 101^{\circ} 55^{\prime} \mathrm{E}\right)$. This program is sponsored by ARPA, and became operational in the summer of 1968 .

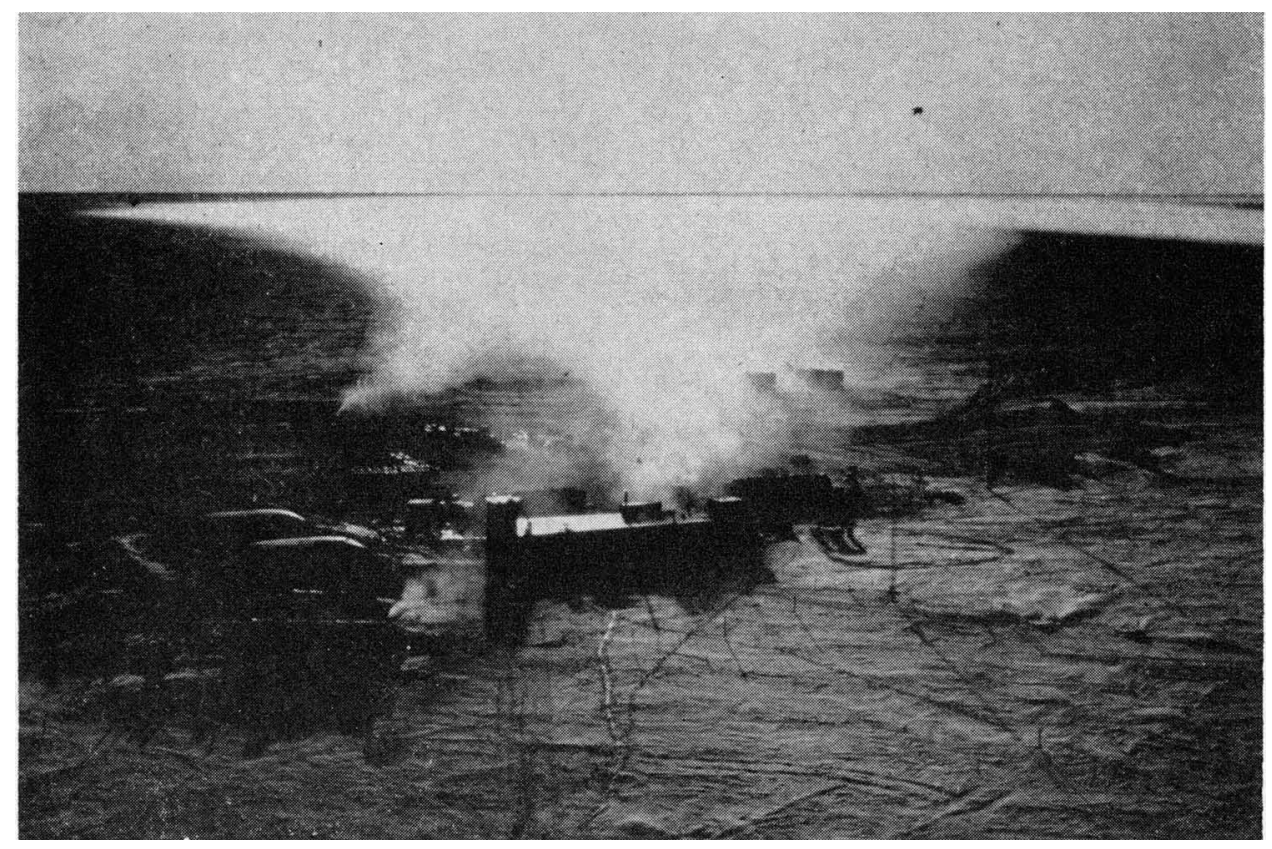

FIG. 1. Aerial shot from atop 103-foot micrometeorological tower at Plateau, East Antarctica, showing the pollution of the air from main camp (in the middle of the photo) and the summer overflow camp (off to the right of the photo). Plateau is located at an elevation of 3624 meters $(11,890 \mathrm{ft})$ at $79^{\circ} 14^{\prime} \mathrm{S}, 40^{\circ} 30^{\prime} \mathrm{E}$, which means that it lies approximately 700 miles beyond the South Pole in the heart of East Antarctica. 
and there are cases where the $2-\mathrm{m}$ wind direction is $180^{\circ}$ different from that at half a meter height. The 1967 data are currently in the process of being analyzed at the Natick Laboratories by Eugene Wong and Leander Stroschein, who are working with Dr. Heinz Lettau of the University of Wisconsin. Tom Frostman will join the analysis team when he returns from the Antarctic in February 1969.

Plateau station was closed by the United States in January 1969, so there were two years of nearly continuous micromet data from the high altitude, high elevation, cold dry desert station. The only major break in data occurred in March of 1968 when a disastrous camp fire wiped out the best generator and necessitated cannibalizing spare parts from two down generators to get back into operation. Meteorologist Tom Frostman was overcome by carbon monoxide poisoning during the camp fire, but was not seriously affected.

In addition to the micrometeorological program, Leander Stroschein had established a large solar radiation program in the summer of 1965-66, which was active for the three years of the station's existence. Michael Kuhn, a student of Dr. Herfried Hoinkes at Innsbruck, has taken over the responsibility of the reduction and analyses of the radiation data. This is being handled at both Natick and in Innsbruck, and is sponsored by the National Science Foundation.
Mention should be made of the overall TREND program in Thailand. ${ }^{1}$ It is a multidisciplinary study of a representative vegetation and climate which are somewhat analogous to those on the Pacific side of the Canal Zone where the Army Tropical Test Center is located. Micrometeorology is the core program, but extensive vegetation studies are being carried out within the study area. Soils are also being studied in some detail, although this is a poor area on the whole to make pedological studies as the soils are so thin. Scientists in the fields of microbiology, mycology, ecology, and entomology are also working on this large project.

TREND's field station consists of some 15 buildings, with complete housing and messing facilities, as well as power plant and water supply system. It is probably the best appointed tropical research station in existence, and it is the only micrometeorological program in Southeast Asia which is operated by "friendly nations." Meteorologists interested in visiting the station to conduct special projects should contact Paul Dalrymple at the U. S. Army Natick (Mass.) Laboratories.

1 See news and notes, Environmental data program in Thailand, Bull. Amer. Meteor. Soc., 49, 1096-1097.

\title{
PROCEEDINGS OF THE THIRD CONFERENCE ON AEROSPACE METEOROLOGY
}

Through a cooperative effort of the American Meteorological Society, the American Institute of Aeronautics and Astronautics and the Institute of Environmental Sciences, the Third Conference on Aerospace Meteorology was held from May 6-9, 1968 in New Orleans, La. This interdisciplinary conference afforded an opportunity for engineers to present their analyses of interactions of the atmosphere with aerospace systems, and for meteorologists to present advancements in their understanding and description of the atmosphere, to aerospace design engineers and operational personnel.

The Proceedings represent papers in the following areas:

\author{
Environment Considerations in Aerospace Program \\ Sensing the Aerospace Environment \\ Wind Profiles-Measurement Systems and Studies \\ Low Level Winds and Wind Measurement Studies \\ Atmospheric Modeling and Spacecraft Interactions \\ Wind Profiles-Aerospace Vehicle Applications \\ Simulation Problems and the Aerospace Environment \\ Problems of Seeing Through the Atmosphere and Sound Propagation \\ Upper Atmosphere (30km) Variability \\ Aircraft Environment Interactions and Atmospheric Turbulence
}

Price: $\$ 20$ nonmembers

580 pages

$\$ 15$ AMS members

SEND ORDERS TO: AMERICAN METEOROLOGICAL SOCIETY, 45 Beacon St, Boston, Mass. 02108 


\section{PROCEEDINGS}

\section{3th RADAR METEOROLOGY}

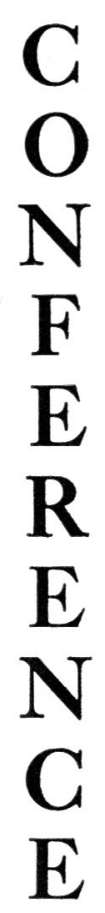

20

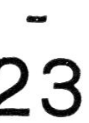

$\mathrm{A}$
$\mathrm{G}$
$\mathrm{S}$
$\mathrm{T}$

1
1
6
8

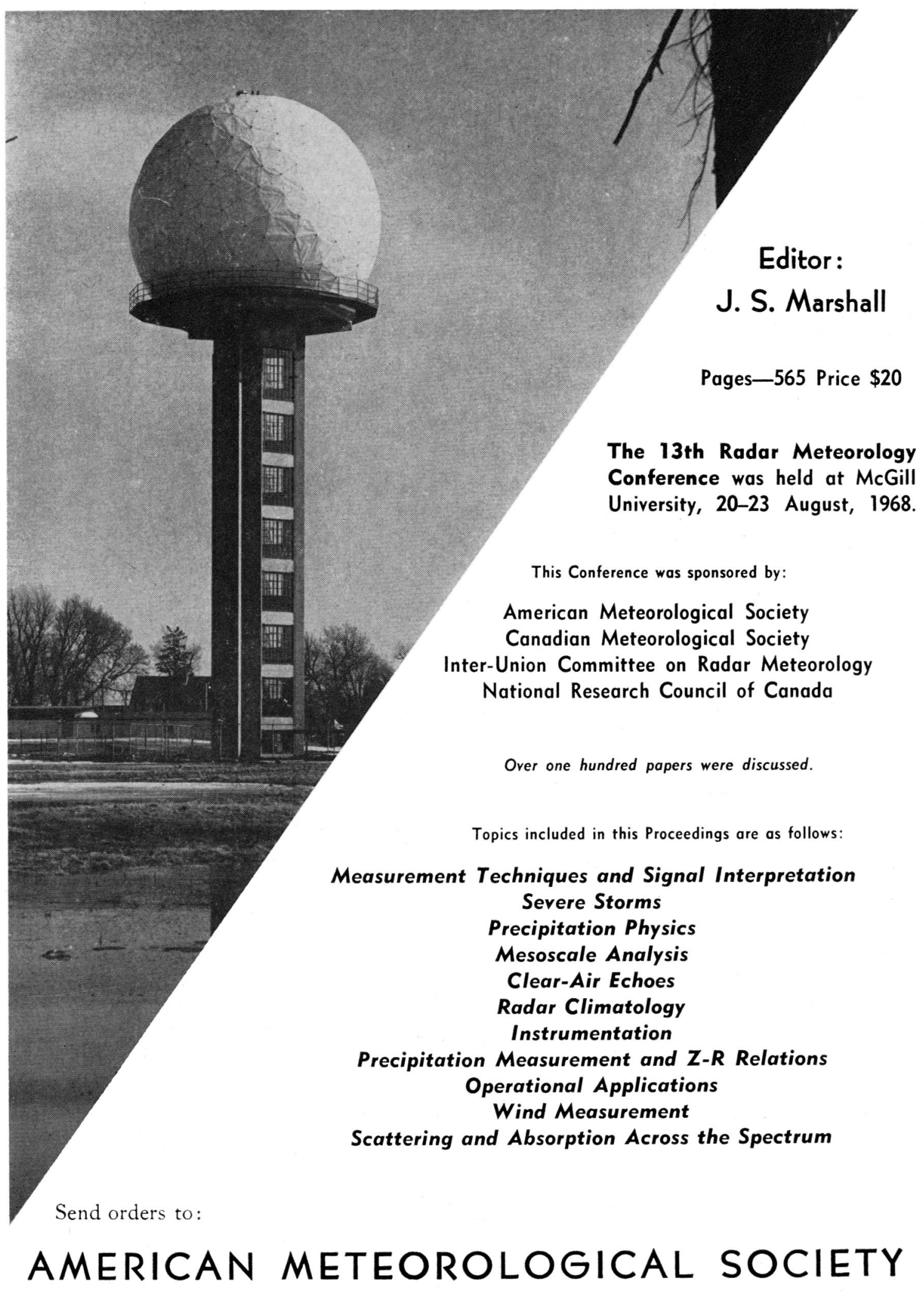

45 BEACON STREET, BOSTON, MASS. 02108 